\title{
Condroblastoma de comportamiento agresivo en cuboides, localización inusual. Reporte de un caso y revisión de la literatura
}

\author{
Aggressive chondroblastoma of the cuboid, unusual \\ location. Case report and literature review
}

Guadalupe de Jesús Cárdenas Padilla, ${ }^{*}$ María Teresa Gonzales Miranda, ${ }^{\ddagger, *}$ Margarita Hernández Mireles§,*

${ }^{*}$ Centenario Hospital Miguel Hidalgo; ¥Ortopedia Oncológica; §Pie y tobillo.

\begin{abstract}
Resumen
Se expone el caso de un condroblastoma de cuboides en una paciente de 15 años. Esta tumoración presenta un comportamiento agresivo, el cual no responde al tratamiento mediante curetaje, injerto óseo y adyuvancia con criocirugía en los tejidos afectados por el tumor. La evolución tórpida obliga posteriormente a realizar una resección radical. A pesar de ser clasificado como una neoplasia benigna agresiva, se hace mención de la posibilidad de metástasis pulmonares y de la agresividad local en algunas situaciones, como la de esta fémina.
\end{abstract}

Palabras clave: Condroblastoma, tumor benigno agresivo, criocirugía.

\begin{abstract}
The case of a cuboid chondroblastoma in a 15-year-old woman is presented. This tumor presents an aggressive behavior which does not respond to treatment by curettage, bone grafting and adjuvant cryosurgery in the tissues affected by the tumor. The torpid evolution subsequently forces the need of a radical resection. Despite being classified as an aggressive benign tumor, a mention is made of the possibility of pulmonary metastases and local aggressiveness in some cases, such as that of this patient.
\end{abstract}

Keywords: Chondroblastoma, benign aggressive tumor, cryosurgery.

\section{Introducción}

El condroblastoma es un tumor benigno, descrito inicialmente en 1928 por Ewing, como tumor de células gigantes calcificado, y en 1931 por Codman, como tumoración condromatosa epifisaria de células gigantes. En 1942, Jaffe y Lichtenstein introducirían el término de condroblastoma benigno como una entidad distinta. La Organización Mundial de la Salud (OMS) lo define en términos de una neoplasia benigna relativamente rara que se caracteriza por un tejido muy celular y relativamente indiferenciado, constituido por células redondeadas o poligonales semejantes a con-

Correspondencia:

Dra. Guadalupe de Jesús Cárdenas Padilla

E-mail: ahtipul.cp@gmail.com

Recibido: 04-04-2021. Aceptado: 14-04-2021. droblastos y por células gigantes multinucleadas de tipo osteoclástico, aisladas o en grupos. En general, se encuentra poco material intercelular, pero es típica la presencia de pequeñas cantidades de matriz cartilaginosa intercelular con zonas de calcificación focal. ${ }^{1-3}$

La incidencia es muy baja y se reporta en $1 \%$ de los tumores de los huesos. Se presenta en la epífisis de los huesos largos, en fémur proximal (25\%), húmero proximal (14.28\%) y tibia (14.28\%). La edad máxima de surgimiento es de 30 años y la mínima de 13 años, con un promedio de 16.5 años. Con un predominio en el sexo masculino de $3: 1$ y en México de 7:1.4,5 

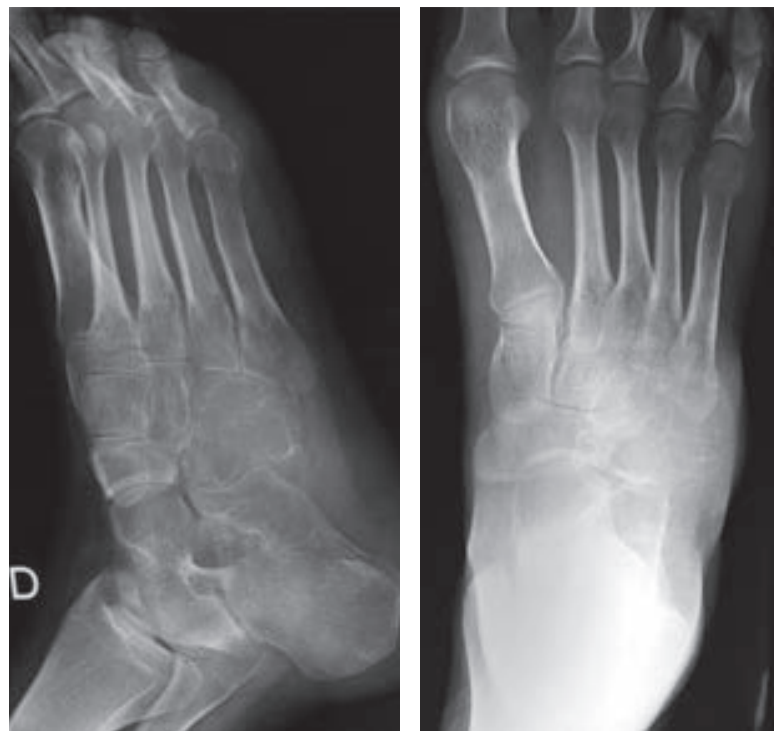

Figura 1: Radiografía lateral de pie derecho inicial muestra tumoración de cuboides.

Radiológicamente, se exhibe con la forma de una lesión excéntrica, radiolucente, con un borde delgado y escleroso, y tiene un patrón geográfico de destrucción ósea bien delimitada; en ciertos casos puede ostentar punteado de calcificaciones. ${ }^{6}$ Su localización en el cuboides es rara, Schajowicz reporta en su estudio que se presenta en $9 \%$ de un total de 660 casos. $^{2}$

El tratamiento de un tumor óseo benigno agresivo no es simple, ya que muchos tienen la característica de recidivar y en algunas ocasiones de sufrir transformaciones malignas. El diagnóstico y atención de los tumores de huesos dependen de una colaboración entre ortopedistas, oncólogos, radiólogos y patólogos. ${ }^{4-6}$ La acometida es fundamentalmente quirúrgica y consiste en resección ósea y curetaje, combinados con o sin aplicación de injerto de hueso, resección y artrodesis y amputación. Los cuatro márgenes quirúrgicos básicos son: intracapsular, marginal, amplio y radical, según plantea Enneking. ${ }^{3} \mathrm{Al}$ realizar el curetaje o legrado del hueso, es importante agregar un adyuvante para disminuir la probabilidad de recidiva local, pueden ser usados desde alcohol (96\%), fenol (80\%), peróxido de hidrógeno, nitrógeno líquido, óxido nitroso e incluso polimetilmetacrilato, este último cumple incluso una función de espaciador local temporal o definitivo. ${ }^{7-9}$

La criocirugía es una técnica quirúrgica que emplea la congelación de los tejidos a temperaturas criogénicas $\left(-30^{\circ} \mathrm{C}\right)$, se inicia la formación de cristales de hielo intracelular, lo que ocasiona la lisis celular, siendo este proceso irreversible con la consecuente muerte celular en el rango de -40 a $70^{\circ} \mathrm{C} .{ }^{10}$

\section{Presentación del caso}

Se trata de un paciente femenino de 15 años de edad, resto de datos sin relevancia dentro del padecimiento actual. Su afección actual inició un año previo a su ingreso al Centenario Hospital Miguel Hidalgo ( $\mathrm{CHMH}$ ), presentaba aumento de volumen en la región lateral de medio pie derecho, secundario a sufrir una inversión forzada del mismo, valorada por facultativo particular quien identificó en la radiografía inicial un menoscabo lítico sin esclerosis a nivel del cuboides (Figura 1), por lo que realizó una toma de biopsia incisional el 24/07/2018 cuyo resultado fue un sarcoma de Ewing, motivo por el cual fue llevada a valoración al $\mathrm{CHMH}$.

En su primera consulta en el $\mathrm{CHMH}$, se observó el pie derecho con aumento de volumen lateral a nivel

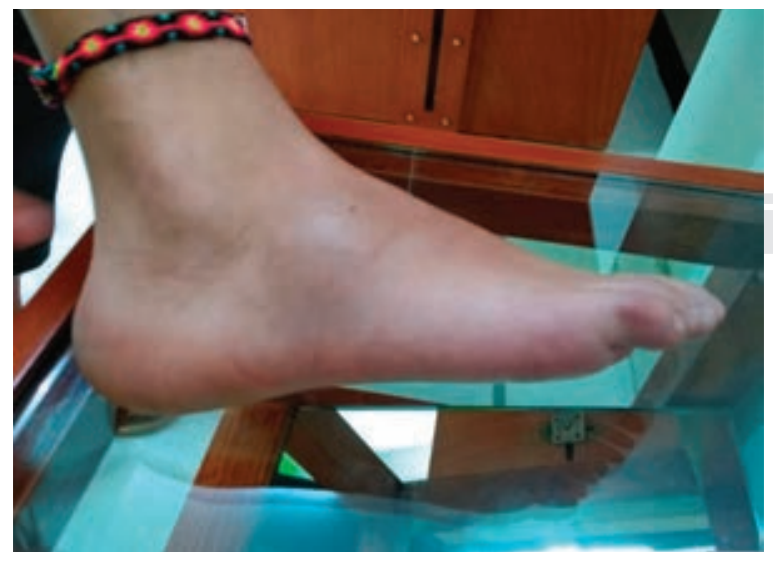

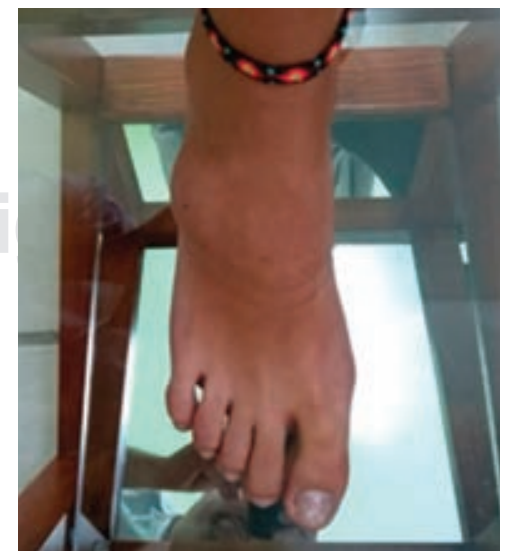

Figura 2:

Imágenes fotográficas

clínicas de pie. 

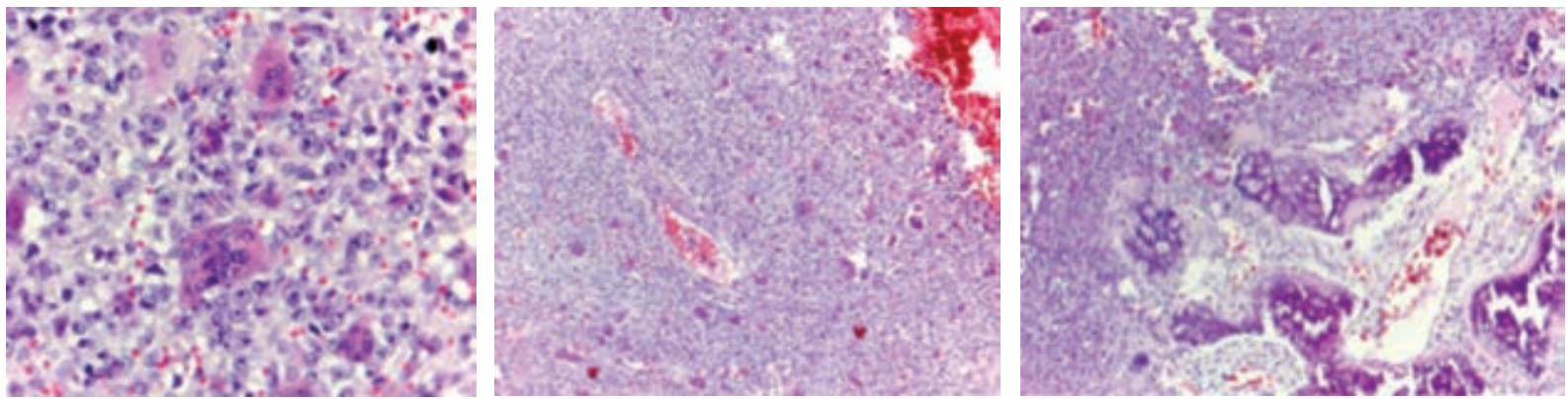

Figura 3: Análisis histopatológico 100x y 400x postoperatorio de lesión. La tinción con hematoxilina y eosina reveló células gigantes poligonales con núcleo ovalado, citoplasma eosinofilico bien definido, áreas de material condroide con zonas de calcificaciones, células condroblastómicas.

del medio pie, una tumoración mal definida de aproximadamente $6 \times 6 \mathrm{~cm}$, fija a planos profundos, de consistencia blanda, dolorosa a la palpación. No había cambios en la coloración de la piel, ni red venosa colateral, se descubrió una antigua cicatriz quirúrgica eutrófica de aproximadamente $4 \mathrm{~cm}$ de longitud justo sobre la tumoración, los arcos de movilidad presentaban limitación y dolor, principalmente a la eversión y flexo extensión de los dedos, con pulso pedio normal y llenado capilar de tres segundos (Figura 2). Durante esa primera consulta en el $\mathrm{CHMH}$, la paciente proporcionó los siguientes estudios: resonancia magnética nuclear de pie, tomada el 06/05/2018: mostrando lesión invasiva en hueso cuboides y cuneiforme, que por sus características corresponde a granuloma eosinofílico versus fibroma condromixoide, con patología maligna a descartar; tomografía axial computarizada de tórax: sin evidencia de actividad tumoral mediastinal ni pulmonar; gammagrama óseo del 15/05/2018: positivo para detección de daño primario en pie derecho, negativo para metástasis. Una segunda biopsia incisional arrojó reporte de condroblastoma de cuboides de dicho pie.

Ya al ser paciente del $\mathrm{CHMH}$, se realizó una tercera biopsia incisional en ese hueso lateral del tarso del pie derecho el 18/09/2018, reportándose por patología del hospital un condroblastoma de tal pie (Figura 3). Se ejecutó un curetaje óseo local de la zona afectada (cuboides) por el tumor, sin encontrar evidencia de invasión a tejidos blandos, así como la colocación de aloinjerto cadavérico y fijación con placa tercio de caña de ocho orificios, fijando el quinto metatarsiano al calcáneo, logrando un reporte postquirúrgico con bordes libres de lesión tumoral (Figura 4). Se dio seguimiento postoperatorio a la primera, tercera y séptima semanas siguientes, manifestando a las siete semanas dehiscencia de herida, al igual que tumefacción, aumento de volumen y dolor en superficie lateral y plantar del medio pie. Se obtuvo un ultrasonido del mencionado pie el 01/07/2019, el cual reportó una colección de $40 \mathrm{~cm}^{3}$ no sólida en la superficie lateral de medio pie.

El 30/07/2019 se practicó biopsia por punción de las zonas con aumento de volumen y patología reportó condroblastoma de pie derecho. El 22/08/2019 se realizó retiro de material de osteosíntesis y del injerto colocado previamente, se practicó legrado en huesos afectados y debridación de tejidos no viables, más adyuvancia con criocirugía (óxido nitroso), y se aplicó en todos los tejidos afectados por el tumor y posteriormente se colocó un espaciador de metilmetacrilato. En el transquirúrgico se identificó compromiso de cuñas, base de segundo al quinto metatarsiano, calcáneo, escafoides y fascia plantar, así como tendones flexores (Figuras 5 y 6). Se continuó el seguimiento a la paciente por ocho semanas, quien evolucionó tórpidamente con dehiscencia de la herida, complicada por múltiples infecciones además de la presencia de tejido tumoral nuevamente. Por decisión de la menor afectada y de su madre, finalmente se deciden por la

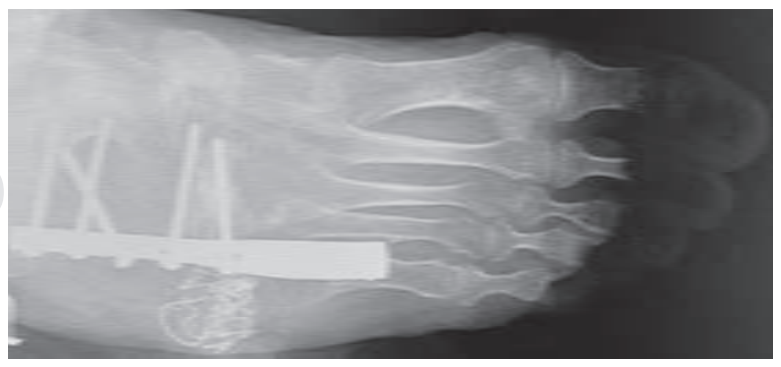

Figura 4: Radiografía proyección oblicua de pie derecho, postquirúrgico inmediato de biopsia excisional y colocación de aloinjerto cadavérico más fijación con placa tercio de caña. 
amputación transtibial. En su última consulta posterior a dicha amputación se encontró a la paciente con muñón adecuadamente moldeado, con ortesis funcional que le permite apoyo bipodálico sin auxiliares para la marcha, esta última con fases y variantes respetadas, y se mantiene sin recidiva tumoral local en un seguimiento postquirúrgico de 10 meses.

\section{Discusión}

El condroblastoma, definido como tal en 1942 por Jaffe y Lichtenstein, presenta un comportamiento benigno pero agresivo, siendo su tratamiento mediante curetaje y aplicación de injerto óseo de la cavidad resultante después del legrado. ${ }^{1}$ A pesar de ser benigno, por su desenvolvimiento agresivo se hace mención de la posibilidad de metástasis en los pulmones y a la agresividad local en algunas ocasiones. .,11-14 $^{2}$

El condroblastoma agresivo es un tumor raro, el cual cuenta con diversos diagnósticos diferenciales, ya que la evolución natural de dicha enfermedad se confunde con otros tumores, su diagnóstico resulta complicado y se realiza en la mayoría de las ocasiones única y definitivamente por estudio histopatológico. El caso reportado coincide con el desenvolvimiento de las tumoraciones benignas agresivas, al igual que el rango de edad 10-15 años, la ubicación en el cuboides resulta poco frecuente. ${ }^{12,15,16}$

El curetaje, o legrado óseo, es el acercamiento quirúrgico más utilizado, con el que se puede tener una recidiva entre $30-70 \%$, por tal motivo se recomienda la aplicación de adyuvantes locales como en el caso de esta paciente (criocirugía, polimetilmetacrilato) lo que disminuye la posibilidad de recidiva $20 \% .{ }^{17,18}$

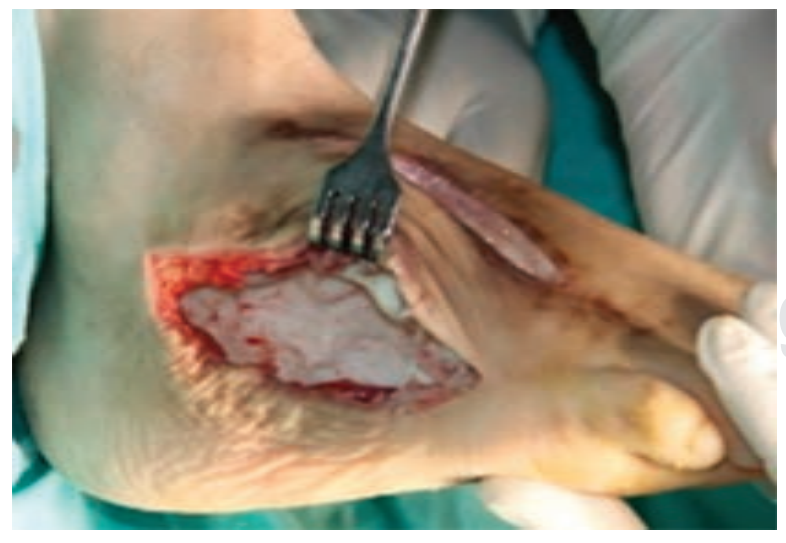

Figura 5: Fotografía lateral de pie derecho, postquirúrgico de crioterapia (óxido nitroso) y colocación de metilmetacrilato (cemento óseo).
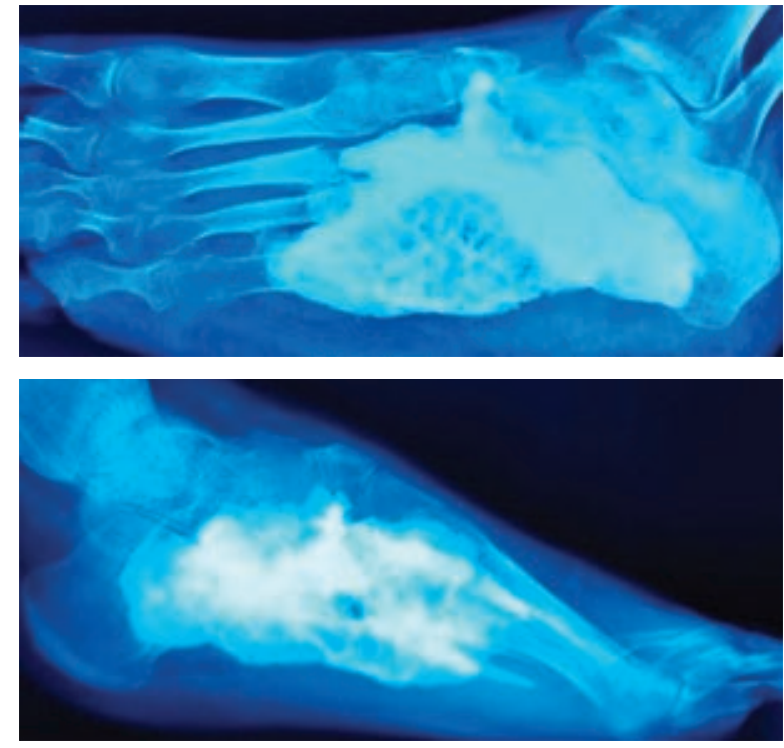

Figura 6: Radiografía oblicua y lateral de pie derecho, postquirúrgico de crioterapia y colocación de metilmetacrilato (cemento óseo).

\section{Conclusiones}

El condroblastoma de cuboides es poco frecuente, de características benignas pero comportamiento tanto agresivo como invasivo; tiene pobre respuesta al tratamiento con resección marginal simple y se debe tomar en cuenta la existencia de formas más agresivas, altamente invasivas. Hay que considerar que el pronóstico de estas tumoraciones está definido por su desarrollo biológico, la probabilidad de recidiva local y la posibilidad de metástasis pulmonares, y se debe tener presente que estos tumores no responden a quimio ni a radioterapia. ${ }^{19,20}$

\section{Referencias}

1. Ramos LP, Sánchez PS. Tumores óseos del pie. Servicio de cirugía ortopédica y traumatología. Complejo asistencial Universitario de León. Revista del Pie y Tobillo. 2011;25 (1): 6-19.

2. Schajowicz F. Tumores y lesiones seudotumorales de huesos y articulaciones. Buenos Aires: Médica Panamericana; 1982, pp. 146-161.

3. Enneking WF. Staging of musculoskeletal neoplasm international skeletal society, division of orthopedic surgery. University of Florida College of Medicine, Gainesville, FL. 1985; 32: 666. doi: 10.1007/BF00350572

4. Mora RFG, Cortes GJ. Condroblastoma primario agresivo, reporte de caso y revisión de la literatura. Rev Mex Ortop Ped. 2008; 10 (1): 5-9.

5. Méndez LJM, Carballo GA, Salva CG. Condroblastoma de astrágalo: localización inusual. Rev Esp Cir Osteoart. 1997; 32: 100-102. 
6. López-Sastre Núñez A, Gómez Robledo J, Ortiz Gómez JA Prieto Montaña JB. Salarrullana Verda J. Condroblastoma benigno del fémur. Rev Ortop Traumatol 1995; 39: 319-322.

7. Zhang K, Gao Y. Chondroblastoma of the Talus: a case report and literature review. The Journal of Foot \& Ankle Surgery. 2012; 51: 262-265

8. Álvarez LA. Tumores óseos primarios. Revisión del tema. AMC. 2003; 7 (2): 215-229.

9. Adler CP, Kozlowski KK. Primary bone tumors and tumorous conditions in children. Berlin: Springer-Verlag; 1993, pp. 9-119.

10. Dittrich RJ. Mecanismo de lesión tisular en criocirugía. Revista de la Asociación Médica Argentina. 2008; 121 (3): 29-39.

11. De Zavala S, Torres J, Bosi S. Condroblastoma a propósito de un caso. Revista Española de Cirugía Osteoarticular. 1983; 18: 47-51.

12. Aronson RS, Hart WS, Martel W. Metaphyseal chondroblastoma. AJR Am J Roentgenol. 1976; 127: 686-688.

13. Huvos, AG, Higinbotham NL, Marcove RC. Agressive behaviour and metastases with report of a new case. Clin Orthop. 1977; 126: 266-272.

14. Reyes CV, Kathuria S. Recurrent on aggressive chondroblastoma of the pelvis with malignant neoplastic changes. Am J Surg Pthol. 1979; 3: 449-455.

15. Fernández JS, Baudet EM, Vilches TJ, Sabate SC, Ayllon GA. Condriblastoma benigno. Rev S Traum Ort. 1988; 8: 253-259. https://www.researchgate.net/profile/Jose-SueiroFernandez/publication/309728238_Condroblastoma_
Benigno/links/5821fe3908aed9ccec638778/CondroblastomaBenigno.pdf

16. Matejovsky Z, Povysil C. Benign and aggressive chondroblastoma. Journal of Bone \& Joint Surgery British. 2004; 86B (Suppl. 3): 270.

17. Toy PC, France J, Randall RL, Neel MD, Shorr RI, Heck RK. Reconstruction of noncontained distal femoral defects with polymethylmethacrylate and crossed-screw augmentation: a biomechanical study. J Bone Joint Surg Am. 2006; 88 (1): 171-178.

18. Moreno LF, Moreno E, Ramírez SO, Tecualt R, Amaya RA, Morfin PA. Tumores óseos benignos de comportamiento agresivo. Orthotips. 2008; 4: 2 .

19. Cates JM, Rosenberg AE, O'Connell JX, Nielsen GP. Chondroblastoma-like chondroma of soft tissue: an underrecognized variant and its differential diagnosis. Am J Surg Pathol. 2001; 25 (5): 661-666.

20. Dahilin DC, Ivins JC. Benign chondroblastoma. A study of 125 cases. Cancer. 1972; 30: 401-413.

\section{Conflicto de intereses}

Los autores no encuentran ningún conflicto de intereses. 